\title{
TORSADE DE POINTES
}

CAUSED BY GLUTEN-SENSITIVE ENTEROPATHY LEADING TO MULTIPLEX ENDOCRINE FAILURE - A CASE REPORT

\section{Éva Csajbók*, Andrea Orosz ${ }^{* *}$, Peter Hankovszky***, László Rudas**, Csaba Lengyel ** *University of Szeged, 1st Department of Internal Medicine, Endocrine Unit,Hungary \\ ${ }^{* *}$ University of Szeged, Department of Pharmacology, Hungary}

Abstact

${ }^{* * *}$ University of Szeged, Department of Anaesthesiology and Intensive Therapy, Hungary

ECG showed 65/min sinus rhythm with negative T waves in the precordial leads. Blood pressure was $70 / 50 \mathrm{~mm} \mathrm{Hg}$. Suddenly torsade de pointes ventricular tachycardia (TdP) occurred, which was converted to sinus rhythm with $300 \mathrm{mg}$ amiodarone.

Coronarography showed no significant stenosis on epicardial coronaries. During the intervention, supraventricular tacyhcardia occurred for $30 \mathrm{~s}$ and disappeared after $150 \mathrm{mg}$ amiodarone, ECGs showed no PQ prolongation 76/min sinus rhythm and diffuse T-wave depression.

Echocardiography found EF 38\%, anterior, inferior, septal akinesis. On the 4th and 7th day of observation 35/min bradycardia occurred with junctional and ventricular extrasystole requiring defibrillation with $200 \mathrm{~J}$. TSH

adrenal insufficiency.
As the suggested diagnosis was polyglandular autoimmune syndrome, we performed autoimmune screening and found anti-transglutaminase antibodies. However, further autoimmune screening showed no sign for other autoimmune disesases. Gluten-free diet, hydrocortisone, levothyroxine, calcium, vitamin D3, and testosterone supplementation started, ICD was implanted. TdP never occurred again.

Last results showed normal Ca, TSH, fT3, fT4 values, mildly lower testosterone, suppressed ACTH and mildly elevated cortisol levels.

Conclusion: We found gluten-enteropathy caused persistent polyglandular endocrine failure leading to torsade de pointes tachycardia requiring reanimation and ICD implantation without having autoimmune origin

\section{Case description}

A 55 year-old man was brought to the emergency room because of hypotension, fatigue, fever pain in the left shoulder.

Previous medical history

He suffered from recurrent arrythmias in the last 5 years, but no alteration was found during the cardiological evaluation. No medication was taken.

Holter ECG showed the following results: VES: total: 669, isolated: 633, coupled: 17, SVES: 142, isolated: 63, coupled: 38. Maximum HR: 132, minimum HR: 47 s, fibrillation: 0 , s run: 0.

Laboratory test showed normal serum $\mathrm{Na}^{+}, \mathrm{K}^{+}, \mathrm{UN}$, kreatinin levels and liver function although $\mathrm{Hb}$ was low $(115 \mathrm{~g} / 1)$.

Gastoscopy foud antral gastritis without any sign of Helicobacter pylori infection.

Stress 99Tc myoview was negative with LVEF: 44\%

5 years later in the emergency room:

(BG): 4.7 , sodium $\left(\mathrm{Na}^{+}\right): 132 \mathrm{mM} /$, potassium $\left(\mathrm{K}^{+}\right): 3.2 \mathrm{mM} /$ levels.

ECter . 5 /

Coronarography was performed and showed no signifcant stenosis on epicardial coronary arteries. During the intervention supraventricular tacyhcardia occured for $30 \mathrm{~s}$, and disappeared after administration of $150 \mathrm{mg}$ amiodarone. In the Intensive Care Unit ECGs showed no PQ prolongation, with 76/min, sinus rythm and diffuse T-wave depression. Amiodarone was given $200 \mathrm{mg}$ BID.

On the 4th day $35 /$ min. bradycardia occured with junctional and ventricular extrasystolia.

On the 7 th day of observation he needed defibrillation with $200 \mathrm{~J}$ because of ventricular fibrillation.

On the 8th day TSH measurement suggested hypothyroidism (TSH: 13.89 mIU//, normal: 0.4-4.2 mlU//), severe hypocalcaemia suggested hypoparathyroidism. Serum total calcium level was:1.82 mM/I (normal: $2.2-2.5)$, PTH:1.5 pM/I

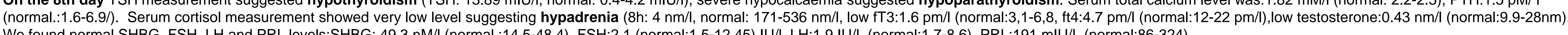

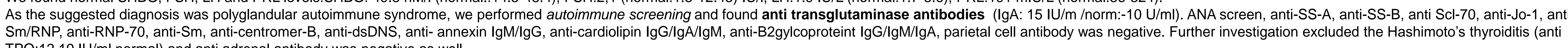
TPO:12.19 I U/mI normal) and anti adrenal antibody was negative as well.

Gluten-free diet was introduced, hydrocortison, levothyroxin, calcium, vitamin d3, testosterone supplementation started, ICD was implanted. TdP never occured again.

After 12 month of treatment and gluten-free diet we tried to stop the hormone supplementation because of the negative antibody screning for polyglandular autommune syndrome, but hypadrenia, hypogonadism and hypothyroidism occurred

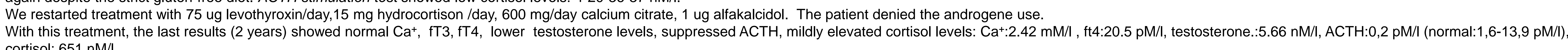
cortisol: $651 \mathrm{nM} / \mathrm{s}$

\section{Conclusion:}

We found gluten-enteropathy caused persistent polyglandular endocrine failure leading to torsade de pointes tachycardia requiring reanimation and ICD implantation without having autoimmune origin.

There is no other patient mentioned in the literature with similar cause of torsade de pointes.

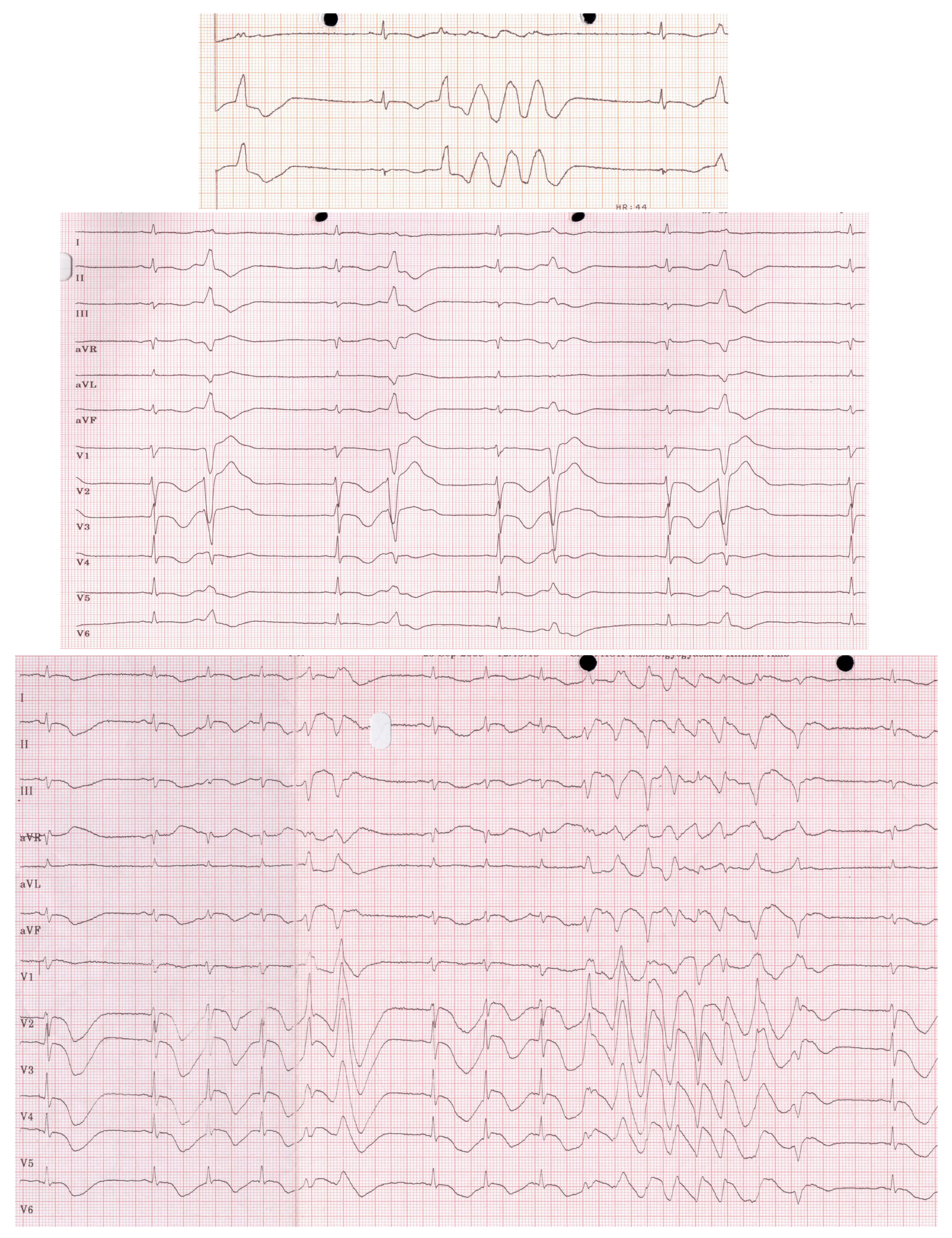

\begin{tabular}{|c|c|c|c|c|}
\hline & ER (torsades) & Endocrine & $\begin{array}{c}\begin{array}{c}\text { Follow-up } \\
\text { (2 year) }\end{array}\end{array}$ & $\begin{array}{c}\text { Referencec } \\
\text { ranges }\end{array}$ \\
\hline Nat $(m M / l)$ & 132 & 133 & 143 & $136-145$ \\
\hline $\mathrm{K}^{+}(\mathrm{mM} / \mathrm{l})$ & 3.2 & 4.7 & 4.5 & $3.5-5.11$ \\
\hline Cat,total(mMII) & 1.82 & 2.36 & 2.3 & $2.2-2.55$ \\
\hline Haematocrit $(L / L)$ & 0.31 & 0.41 & 0.39 & $0.39-0.55$ \\
\hline TSH (mIU/) & 13.89 & 0.28 & 3.03 & $0.4-4.2$ \\
\hline $\mathrm{fT} 4(\mathrm{pM} /)$ & 6 & 20.5 & $21-4$ & $12-22$ \\
\hline Cortisol (nMI) & 4 & 100 & 651 & 171-536 \\
\hline ACTH $(\mathrm{pM} / \mathrm{l})$ & - & 1.07 & 0.22 & $1.6-13.9$ \\
\hline PTH $(\mathrm{pm} / \mathrm{l})$ & 1.5 & & 1 & $1.6-6.9$ \\
\hline FSH (IUI) & 2.1 & 3.1 & 1.9 & $1.5-12.45$ \\
\hline LH(IUI) & 1.9 & 2 & 3.1 & $1.7-8.6$ \\
\hline Testosterone $(\mathrm{nM} / \mathrm{l})$ & 0.43 & 1.1 & 13.01 & $9.9-28$ \\
\hline SHBG (nM/l) & 49.3 & 36.4 & 52 & 14.5-48.4 \\
\hline Maintenance therapy (daily) & & 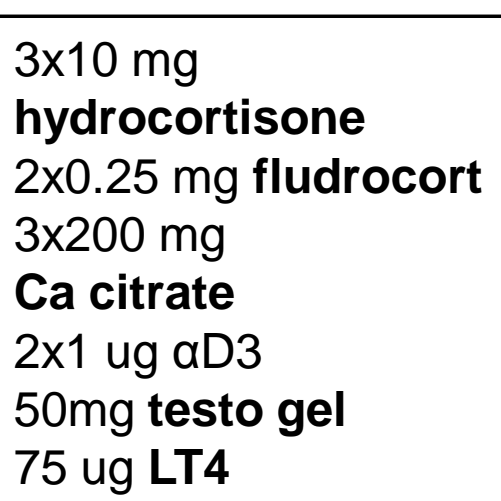 & \begin{tabular}{|l|}
$10-5 \mathrm{mg}$ \\
hydrocortisone \\
3 3200 mg \\
Ca citrate \\
1 ug aD3 \\
75 ug LT4
\end{tabular} & \\
\hline
\end{tabular}

Background It is often associated with a prolonged QT interval, which may be congenital or acquired.

ORS complexes varies from beat to beat. The ventinto ventricular fibrillation.

The original report described regular variation of the morphology of the QRS vector from positive to nenge from 150 beats per minute (bpm) to $250 \mathrm{bpm}$

The definition also requires that the QT interval be increased markedly (usually to $600 \mathrm{msec}$ or greater).

Torsade usually occurs in bursts that are not sustained; thus, the rhythm strip usually shows the patient's baseline QT prolongation.

References

1. Kandan SR, Saha M. Severe primary hypothyroidism presenting with torsades de pointes; BMJ Case Rep. 2012 Sep 17;2012. doi:pii: bcr1220115306. 10.1136/bcr.12.2011.5306.

2. Sauer AJ, Newton-Cheh C.:Clinical and genetic determinants of torsade de pointes risk; Circulation. 2012 Apr 3;125(13):1684-94. doi: 10.1161/CIRCULATIONAHA. 111.080887. Review.

3. Sharma S, Gulati S.:The ketogenic diet and the QT interval; J Ilin Neurosci. 2012 Jan; 19(1):181-2. doi: 10.1016/j/jocn.2011.05.012.
4. Pecori Giraldi F et al: High prevalence of prolonged QT interval duration in male patients with Cushing's disease; Exp Clin Endocrinol Diabetes. 2011 Apr;119(4):221-4. doi: 10.1055/s-0031-1271628.

5. Kornelius E, Chen KS, Yang YS. Huang CN.:Torsade de pointes--a rare presentation of primary hyperaldosteronism; Am J Emerg Med. 2012 Jan:30(1):257. e5-7. doi: 10.1016//.ajem.2010.10.026.

6. Michiels V, Miljoen H, Vrints C.:8. Gastroenteritis with severe consequences: a case of sotalol-induced torsades de pointes; Acta Cardiol. 2009 Dec;64(6):839-42.

7. Yang PC, Kurokawa J, Furukawa T, Clancy CE.:Acute effects of sex steroid hormones on susceptibility to cardiac arrhythmias: a simulation study;:PLoS Comput Biol. 2010 Jan 29;6(1): 1000658. doi:10.1371/journal.pcbi.1000658.

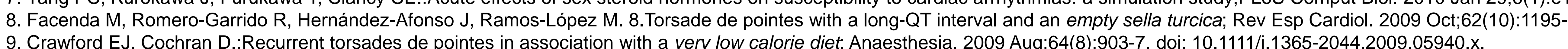

9. Crawtord EJ, Cochran D.Recurrent torsades de pointes in association with a very low calorie diet, Anaesthesia. 2009 Aug;64(8): $903-7$. doi: 10.1111/.1365-2044.2009.05940.X.
10.Methe H, Hinterseer M et al: Torsades de Pointes: a rare complication of an extra-adrenal pheochromocytoma; Hypertens Res. 2007 Dec;30(12):1263-6. doi: 10.1291/hypres.30.1263.

Contact: Eva Csajbók, MD; 1st Dept. of Internal Medicine, University of Szeged, Hungary.

Correspondece: ecsajbok@freemail hu 